\title{
Production of lipase from Streptomyces
}

\begin{abstract}
Lipases constitute an important group of biocatalysts for biotechnological applications. This enzyme can be produced by plants, animals, and microorganisms. However, microbial lipases are the most studied and occupy the center attraction because of their stability, selectivity, and broad substrate specificity. Streptomyces are filamentous Gram-positive bacteria found generally in the soil. This microorganism is known mainly for their capacity to synthesize of numerous antibiotics and other secondary metabolites. They also produce a large number of enzymes such as lipases, which makes Streptomyces a genus with significant biotechnological potential.
\end{abstract}

Keywords: lipase activity, lipase production, Streptomyces, biotechnology
Volume 6 Issue 2 - 2018

\section{Eliton da Silva Vasconcelos,' Raquel Fernanda Salla, ${ }^{2}$ Isara Lourdes Cruz- Hernández ${ }^{3}$ \\ 'Department of Physiological Sciences, Federal University of São Carlos, Brazil \\ ${ }^{2}$ Department of Animal Biology, State University of Campinas, Brazil \\ ${ }^{3}$ Department of Chemical Engineering, Federal University of São Carlos, Brazil}

Correspondence: Eliton da Silva Vasconcelos, Department of Physiological Sciences, Federal University of São Carlos, SP, Brazil,Tel +55 16335 I 8968, Email elitonbio@hotmail.com

Received: January 30, 2018| Published: March 19, 2018

\section{Introduction}

Enzymes are considered as nature's catalysts and the most enzymes are produced by the fermentation of bio based material. Lipases are unique in catalyzing the hydrolysis of fats into fatty acids and glycerol at the water-lipid interface and reversing the reaction in non-aqueous media. Lipolytic enzymes are involved in the breakdown and thus in the mobilization of lipids within the cells of individual organisms as well as in the transfer of lipids from one organism to another.

Lipases are ubiquitous in nature and are produced by several plants, animals, and microorganisms. Lipases of microbial origin represent the most widely used class of enzymes in biotechnological applications and organic chemistry. ${ }^{2}$ Lipases have emerged as one of the leading biocatalysts with proven potential for contributing to the multibillion-dollar underexploited lipid technology bio-industry and have been used in situ lipid metabolism and ex-situ multifaceted industrial applications. ${ }^{3}$ Lipases are generally produced on lipidic carbon, such as oils, fatty acids, glycerol or tweens in the presence of an organic nitrogen source. ${ }^{4}$

Many microorganisms are known as potential producers of extracellular lipases, including bacteria, yeast, and fungi. Fungal species are preferably cultivated in solid-state fermentation, while bacteria and yeast are cultivated in submerged fermentation. ${ }^{5}$ Among several lipases reported from wide varieties of sources, microbial lipases occupy the central attraction regarding their broad biotechnological applications. Microbial lipases constitute an important group of biotechnologically valuable enzymes, mainly because of the versatility of their applied properties and ease of mass production. Microbial lipases are widely diversified in their enzymatic properties and substrate specificity, which make them very attractive for industrial applications. ${ }^{1,6}$

\section{Lipase production and activity in Streptomyces}

The genus Streptomyces (phylum: Actinobacteria) are Grampositive bacteria, high $\mathrm{G}+\mathrm{C}(70 \%)$ genome content, soil-living bacteria with characterized branching filamentous morphology. Streptomyces sp. has a great potential in producing a diverse range of secondary metabolites including antibiotics, antitumor agents, antiparasitic, immunosuppressive agents, and a large number of extracellular enzymes which are essential to the degradation of biomass to assimilable carbon moieties. Generally, these enzymes are hydrolases such as cellulases, xylanases, ligninases, amylases, lipases, nucleases etc. Therefore, Streptomyces is widely recognized as an industrially important microorganism. ${ }^{7,8}$

Cho et al. ${ }^{6}$ isolated from the soil a newly Streptomyces strain, called Streptomyces sp. CS326. To produce lipase, the strain was cultured at $28^{\circ} \mathrm{C}$ for $168 \mathrm{~h}$ on a rotary shaker maintained at $180 \mathrm{rev}$ $\mathrm{min}^{-1}$. The culture medium $(1 \mathrm{~L})$ was supplemented with $10 \mathrm{~g}$ glucose, $10 \mathrm{~g}$ soybean, $0.1 \mathrm{~g} \mathrm{Na}_{2} \mathrm{HPO}_{4}$ and distilled water. The author found an extracellular lipase and this enzyme was purified using a single step gel permeation chromatography on Sepharose CL-6B. The molecular weight of this lipase was estimated to be $17,000 \mathrm{Da}$ by SDS-PAGE. The activity was optimum at $40^{\circ} \mathrm{C}$ and $\mathrm{pH} 7.0$ and was stable at $\mathrm{pH}$ 5.0-8.0 and below $50^{\circ} \mathrm{C}$ and the substrate preferred was p-nitrophenyl palmitate $(\mathrm{C} 16)$.

Streptomyces sp. TEM 33 strain was isolated from soil by Cadirci et al. ${ }^{9}$ The lipase production was performed by Solid State Fermentation (SSF) and the activity was measured $1.74 \pm 0.0005 \mathrm{U} /$ gram dry substrate (gds) by pNPP method on the 6th day of fermentation with $71.43 \%$ final substrate moisture content. According to the authors, the advantage of SSF is that this media is similar to the natural habitat. In addition, in industrial process SSF offers distinct advantages over 
submerged fermentation including economy of the space needed for fermentation; simplicity of the fermentation media; no requirement for complex machinery, equipments and control systems; greater compactness of the fermentation vessel owing to a lower water volume; greater product yields; reduced energy demand; lower capital and recurring expenditures in industry; easier scale up processes; lesser volume of solvent needed for product recovery; superior yields; absence of foam build-up and easier control of contamination due to the low moisture level in the system.

Mishra \& Gupta $^{10}$ isolated 105 Streptomyces from different samples (water, soil, and plants), after screened for lipase production, the S. halstedii strain ST 40 exhibited higher activity. The authors used nine different types of substrates viz., Tween 20, 40, 60 and 80 , mustard oil, sunflower oil, soya bean oil, ghee and olive oil were as inducers substrate into the medium. The results showed that the substrate Tween 20 showed the highest enzyme activity i.e. $1.6 \mathrm{IU} / \mathrm{ml}$ at $4 \mathrm{~h}$ of incubation.

Vishnupriya et al. ${ }^{11}$ studied the lipase production from Streptomyces griseus using olive oil, palm oil, and sunflower oil as substrates. The production of lipase was performed in orbital shaker $96 \mathrm{hrs}$ and the production was optimum at $72 \mathrm{~h}$ of incubation by using olive oil as a substrate and the enzyme activity was found to be $117.88 \mathrm{U} / \mathrm{ml}$. On the other hand, using sunflower oil and palm oil the maximum production was obtained at $24 \mathrm{~h}$ and 48 hours of the incubation period and their enzyme activity were 51.90 and $51.90 \mathrm{U} / \mathrm{ml}$ respectively.

Dos Santos et al. ${ }^{12}$ evaluated a wild-type Streptomyces clavuligerus strain in submerged fermentation using an orbital shaker. After $36 \mathrm{~h}$ of fermentation, the lipase hydrolytic activity was $3000 \mathrm{UL}^{-1}$, measured at $\mathrm{pH} 9.0$ and $37^{\circ} \mathrm{C}$ by using p- nitrophenyl palmitate (pNPP) as substrate. In another study with $S$. clavuligerus, Vasconcelos et al. ${ }^{13}$ compared the extracellular lipase enzymatic activity by spectrophotometry using pNPP as substrate between wild-type and mutant MMS 150 strain, using the complex culture medium proposed by ${ }^{14}$ When cultivated in complex medium, the mutant strain presented less lipolytic activity in comparison with the wild-type. However, when cultivated in the modified complex medium (lacking glycerol), mutant strain showed a lipase production about 2.4 times higher than that of the wild-type. These results show that the mutation caused a greater lipolytic activity depending on the composition of the culture medium.

\section{Conclusion}

Microbial lipases have a great biotechnological potential, ranging from the use of laundry detergents to stereospecific biocatalysts. The genus Streptomyces represents an extremely versatile group of bacterial extracellular enzymes that are capable of performing a variety of important reactions, thereby presenting a captivating field for future studies. Although studies have been growing in this sense, much research is still necessary to determine the full extent of lipase production and activity with genus Streptomyces.

\section{Acknowledgements}

None.

\section{Conflict of interest}

There is no conflicts to publish the article in this Journal.

\section{References}

1. Hasan F, Shah AA, Hameed A. Industrial applications of microbial lipases. Enzyme Microb Technol. 2006;39(2):235-251.

2. Treichel H, Oliveira D, Mazutti MA, et al. A review on microbial lipases production. Food Bioproc Tech. 2010;3(2):182-196.

3. Joseph B, Ramteke P W, Thomas G. Cold active microbial lipases: Some hot issues and recent developments. Biotechnol Adv. 2008;26(5):457-470.

4. Gupta R, Gupta N, Rathi P. Bacterial lipases: an overview of production, purification and biochemical properties. Appl Microbiol Biotechnol. 2004;64(6):763-781.

5. Abada EA. Production and characterization of a mesophilic lipase isolated from Bacillus stearothermophilus AB-1. Pak J Biol Sci. 2008;11(8):1100-1106.

6. Cho SS, Park DJ, Simkhada JR, et al. A neutral lipase applicable in biodiesel production from a newly isolated Streptomyces sp. CS326. Bioprocess Biosyst Eng. 2012;35(1-2):227-234.

7. Tan LT, Chan KG, Lee LH, et al. Streptomyces bacteria as potential probiotics in aquaculture. Front Microbiol. 2016;7:79.

8. Williams ST, Goodfellow M, Alderson G, et al. Numerical classification of Streptomyces and related genera. J Gen Microbiol. 1983;129(6):1743-1813.

9. Cadirci BH, Yasa I, Kocyigit A. Streptomyces sp. TEM 33 possesses high lipolytic activity in solid-state fermentation in comparison with submerged fermentation. Prep Biochem Biotechnol. 2016;46(1):2329.

10. Mishra S, Gupta N. Inducers for the enhanced production of lipase by Streptomyces isolated from mangrove ecosystem. Int $J$ Curr Microbiol App Sci. 2014;3(11):370-376.

11. Vishnupriya B, Sundaramoorthi C, Kalaivani M, et al. Production of lipase from Streptomyces griseus and evaluation of bioparameters. Int J Chemtech Res. 2010;2(3):1380-1383.

12. Dos Santos JBC, Silva CRG, Tardioli PW. Production of whole-cell lipase from Streptomyces clavuligerus in a bench-scale bioreactor and its first evaluation as biocatalyst for synthesis in organic medium. Appl Biochem Biotechnol. 2017;183(1):218-240.

13. Vasconcelos ES, Lima VA, Goto LS, et al. Clavulanic acid production by the MMS 150 mutant obtained from wild type Streptomyces clavuligerus ATCC 27064. Braz J Microbiol. 2013;44(4):1049-1057.

14. Maranesi GL, Baptista-Neto A, Hokka CO, et al. Utilization of vegetable oil in the production of clavulanic acid by Streptomyces clavuligerus ATCC 27064. World J Microbiol Biotechnol. 2005;21(4):509-514. 